\title{
Impact of Weight Loss on Physical Function with Changes in Strength, Muscle Mass, and Muscle Fat Infiltration in Overweight to Moderately Obese Older Adults: A Randomized Clinical Trial
}

\author{
Adam J. Santanasto, ${ }^{1}$ Nancy W. Glynn, ${ }^{1}$ Mark A. Newman, ${ }^{1}$ Christopher A. Taylor, ${ }^{1}$ \\ Maria Mori Brooks, ${ }^{2}$ Bret H. Goodpaster, ${ }^{3}$ and Anne B. Newman ${ }^{1}$ \\ ${ }^{1}$ Department of Epidemiology, Graduate School of Public Health, Center for Aging and Population Health, University of Pittsburgh, \\ 130 N. Bellefield Avenue, Pittsburgh, PA 15260, USA \\ ${ }^{2}$ Department of Epidemiology, Graduate School of Public Health, University of Pittsburgh, A530 Crabtree Hall, 130 DeSoto Street, \\ Pittsburgh, PA 15261, USA \\ ${ }^{3}$ Department of Medicine, School of Medicine, University of Pittsburgh, N807 Montefiore, Pittsburgh, PA 15213, USA
}

Correspondence should be addressed to Nancy W. Glynn, glynnn@edc.pitt.edu

Received 2 May 2010; Accepted 3 September 2010

Academic Editor: Robert J. Ross

Copyright ( $) 2011$ Adam J. Santanasto et al. This is an open access article distributed under the Creative Commons Attribution License, which permits unrestricted use, distribution, and reproduction in any medium, provided the original work is properly cited.

Purpose. Evaluate the effects of weight loss on muscle mass and area, muscle fat infiltration, strength, and their association with physical function. Methods. Thirty-six overweight to moderately obese, sedentary older adults were randomized into either a physical activity plus weight loss $(\mathrm{PA}+\mathrm{WL})$ or physical activity plus successful aging health education $(\mathrm{PA}+\mathrm{SA})$ program. Measurements included body composition by dual-energy X-ray absorptiometry, computerized tomography, knee extensor strength, and short physical performance battery (SPPB). Results. At 6 months, PA+WL lost greater thigh fat and muscle area compared to PA+SA. PA+WL lost $12.4 \%$ strength; PA+SA lost $1.0 \%$. Muscle fat infiltration decreased significantly in PA+WL and $\mathrm{PA}+\mathrm{SA}$. Thigh fat area decreased 6-fold in comparison to lean area in PA+WL. Change in total SPPB score was strongly inversely correlated with change in fat but not with change in lean or strength. Conclusion. Weight loss resulted in additional improvements in function over exercise alone, primarily due to loss of body fat.

\section{Introduction}

The prevalence of obesity in older adults has been rising steadily. In 2000, 22.9\% of individuals between the ages of 60-69 and $15.5 \%$ of those ages 70 and older were classified as obese. These are increases of $56 \%$ and $36 \%$, respectively, since 1991 [1]. Activities of daily living (ADL) impairment due to obesity are estimated to increase by $17.7 \%$ for men and $21.8 \%$ for woman from 2000 to 2020 if this obesity trend continues [2]. The rising prevalence of obesity and obesityrelated ADL disability in older adults makes the prevention and "treatment" of obesity in older adults a very important public health issue.

In addition to obesity, the loss of muscle strength is an important independent risk factor for mortality [3] and incident mobility limitation in older adults [4]. Sarcopenia, the loss of muscle mass with age, is thought to be the primary reason for age-related declines in muscle strength $[5,6]$; however, loss of strength cannot exclusively be attributed to the loss of muscle mass [7]. Goodpaster et al. have shown in the Health, Aging and Body Composition (Health ABC) Study that an increase in muscle fat infiltration, manifested by decreased muscle density or attenuation values [8], is an important predictor of muscle strength independent of muscle mass [9].

Age-related declines in muscle strength, muscle mass, and muscle density can be attenuated or prevented with a regular structured physical activity program consisting of walking, resistance strength training, and balance training [10]. Additionally, it has been suggested that obesity 
compounds the effects of sarcopenia on physical disability and impairment in older adults [11, 12]. This finding is problematic because the loss of muscle or lean mass is accelerated by weight loss (WL) in older adults [13]. However, it has been shown by Chomentowski et al. that this accelerated muscle loss can be attenuated with moderate aerobic exercise [14]. It has also been demonstrated that a WL intervention with moderate physical activity (PA) can improve physical function in older adults with knee osteoarthritis despite losing lean mass [15]. Furthermore, WL and regular PA have been shown to improve function in frail older adults [16]. A gap in knowledge is the combined effect of WL and PA compared with PA alone, on body composition, strength, and function in older adults. This is important because the loss of lean mass associated with WL could lead to the loss of strength, mobility, and function in the older adult population. The potential risks and benefits of weight loss in overweight to moderately obese older adults should be tested in the context of a physical activity program designed to optimally preserve body composition and improve mobility and function.

The primary aim of this study was to determine the effects of weight loss plus physical activity compared to physical activity with a successful aging (SA) health education program on function, muscle mass, muscle fat infiltration, and strength in older adults. Additionally, we examined the association between change in muscle mass, muscle fat infiltration, and fat mass with change in function and strength.

\section{Materials and Methods}

2.1. Participants. Community dwelling older men and woman age 60 and over, who were overweight to moderately obese (body mass index between 28.0 and $39.9 \mathrm{~kg} / \mathrm{m}^{2}$ ) and living a sedentary lifestyle (formal exercise less than $3 \mathrm{x} /$ week for a total of less than $90 \mathrm{~min} /$ week), were recruited from the greater McKeesport, PA area to participate in a one-year randomized clinical trial. Initial eligibility criteria included the self-reported ability to walk $1 / 4$ mile (2-3 blocks), completion of a 400-meter walk in less than 15 minutes without assistance from another person or the use of an assistive device, successful completion of a behavioral run-in, which included an activity log and food diary, the willingness to be randomized to either intervention group, as well as attend meetings and physical activity sessions in McKeesport, PA. Participants were excluded if they failed to provide informed consent, had diabetes requiring insulin, history of diabetic coma, uncontrolled diabetes (defined as a fasting blood sugar greater than $300 \mathrm{mg} / \mathrm{dl}$ ), severe kidney disease that required dialysis, or severe hypertension (systolic blood pressure $>180 \mathrm{mmHg}$ or diastolic blood pressure $>100 \mathrm{mmHg}$ ). Further, significant cognitive impairment (known diagnosis of dementia or a modified minimental state exam score $<80$ ), and other conditions impairing understanding and communication were also exclusions. Other significant comorbid disease severe enough to impair ability to participate in an exercise-based intervention resulted in exclusion. Any person who developed chest pain or severe shortness of breath during $400 \mathrm{~m}$ walk test was also excluded. Participants were also ineligible if a member of their household was already enrolled in the study, if they were currently participating in another intervention trial, planned to move in the next year, had lost more than 10 pounds in the past 4 months, or were taking any drugs for the treatment of obesity.

Participants who met the above were randomly assigned into one of two intervention programs: physical activity plus weight loss $(\mathrm{PA}+\mathrm{WL})$ or physical activity plus a successful aging health education program $(\mathrm{PA}+\mathrm{SA})$. Randomization was done using a Microsoft Access-based random-number generating algorithm with stratification by age and sex to further ensure balance between groups (Microsoft Redmond, Washington). All of the methods described in this paper were implemented following approval by the University of Pittsburgh's Institutional Review Board.

\subsection{Physical Activity Program. All participants, regardless of} the randomized group assignment, participated in identical physical activity programs. The PA program combined aerobic, strength, balance, and flexibility exercises [17]. In brief, the PA program focused on treadmill walking of at least $150 \mathrm{~min} / \mathrm{wk}$ as the primary mode of activity. To complement the walking, participants completed lower extremity resistance training, balance training exercises, and stretching.

The program was divided into three phases: adoption (weeks 1-8), transition (weeks 9-24), and maintenance (weeks 25-52), which were designed to gradually transition exercise out of the clinic setting and into the participant's daily routine. During the adoption phase, all participants were required to attend three center-based exercise sessions per week, which averaged 60 minutes per session. For the transition phase, center-based sessions were reduced to two sessions per week. During this phase, the center-based sessions were supplemented with one or more home-based sessions. The home-based sessions were to be similar to the center-based sessions. During the maintenance phase of the program, participants were invited to attend an optional exercise session at the center once per week, but were expected to engage in physical activity at least three times per week.

2.3. Weight Loss Intervention. Those randomized into the $\mathrm{PA}+\mathrm{WL}$ arm participated in a healthy-eating WL intervention, in addition to the PA program described above. Participants attended 24 weekly, 2 bimonthly, and 5 monthly sessions, which were lead by the study nutritionist. During these meetings, strategies to achieve the recommended caloric intake were discussed and performance in the weight loss intervention was assessed. The nutritionist scheduled one-on-one sessions if a participant was having difficulty adhering to the $\mathrm{WL}$ intervention.

The WL intervention was designed to promote weight reduction and decrease lipid levels. The calorie and fat gram goals were developed by the Diabetes Prevention Program [18]. Based on baseline weight, participants were assigned 
one of the following daily goals: 1200 calories and 33 fat grams, 1500 calories and 42 fat grams, 1800 calories and 50 fat grams, or 2000 calories and 55 fat grams. Total daily fat intake was limited to approximately 25\% of total calories. An emphasis was put on the consumption of monoand polyunsaturated fats while limiting saturated fat and cholesterol. In addition, participants were asked to include at least 5 servings of fruits or vegetables and 6 servings of grains, especially whole grains, in their daily diets. To ensure that participants met daily nutrient recommendations, ageappropriate multivitamin/mineral and calcium/vitamin D supplementation was recommended.

The goal of the WL intervention was a $7 \%$ reduction in body weight at the rate of 1 to 2 pounds per week during the first six months of the intervention. The goal for the remaining six months was to assist participants in achieving and maintaining their weight goal. Participants were required to keep food diaries at least six days per week during the first six months of the intervention and then for a minimum of once a month for the remainder of the study. Self-monitoring of caloric intake was emphasized and participants were encouraged to weigh themselves weekly at home. In addition, participants were weighed once a week by the study nutritionist at the start of the nutrition sessions. Overall adherence to this arm of the intervention was gauged by examining the percentage of participants who met the weight loss goal.

\subsection{Successful Aging (SA) Health Education Intervention.} Participants randomized into the $\mathrm{PA}+\mathrm{SA}$ arm participated in a successful aging health education workshop series in addition to the PA program described above. The workshops were based on "The Ten Keys to Healthy Aging" [19], and the SA intervention used in the Lifestyle Interventions and Independence for Elders Pilot Study (LIFE -P) [17]. Topics included cholesterol, diabetes, blood pressure, bone and muscle health, smoking, cancer screening, social contact, depression, immunizations, and physical activity. Participants enrolled in this study arm attended 1 session per month, for a total of 12 sessions in addition to their physical activity sessions.

2.5. Clinical Measurements. At the baseline (BL) screening visit and followup visits, body height $(\mathrm{cm})$ was measured using a wall-mounted stadiometer and body weight (kg)with a standard certified calibrated scale and were used to calculate BMI (weight $(\mathrm{kg}) /$ height $\left(\mathrm{m}^{2}\right)$ ). Waist circumference $(\mathrm{cm})$ was also measured at BL and followup using the Gulick II Tape Measure (Country Technology Inc., Gray Mills, WI). Waist circumference was measured twice and rounded to the nearest $0.1 \mathrm{~cm}$; if the two measurements had a difference greater than $5 \mathrm{~cm}$, then a third measurement was obtained. The Short Physical Performance Battery (SPPB), a validated measure of lower extremity functional disability in older adults, was performed and included a $4 \mathrm{~m}$ walk, chair stands, and a balance test. More details concerning the SPPB can be found elsewhere [20]. Participants also completed questionnaires on sociodemographic data, medical and hospitalization history, and the Community Healthy Activities Model Program for Seniors (CHAMPS) physical activity questionnaire [21]. The CHAMPS was used to quantify amount of physical activity as well as assess adherence to the PA program [22]. Activities performed at or above 3.0 metabolic equivalents (METs) were defined as moderate physical activity; the type of physical activity the program was designed to deliver. A resting ECG and a physical exam and interview with a nurse practitioner were conducted, before being medically cleared to participate in the physical activity intervention by the study physician.

2.6. Dual Energy X-Ray Absorptiometry (DXA). Total body fat mass, percent body fat, total lean body mass, appendicular lean body mass, total body bone mineral density (BMD), and total hip BMD were assessed using DXA (Hologic QDR 4500, software version 12.3; Bedford, MA). Bone mineral content was subtracted from the total and appendicular lean mass to define total nonbone lean mass, which represents primarily skeletal muscle in the extremities [23]. Appendicular lean mass was defined as the sum of upper and lower extremity lean mass [24].

2.7. Computed Tomography (CT). At BL and followup visits, axial CT scans (9800 Advantage, General Electric, Milwaukee, WI) were obtained and used to measure cross-sectional abdominal visceral and subcutaneous adipose tissue (VAT and SAT) areas using an established method [25]. Briefly, a cross-sectional scan at $10 \mathrm{~mm}$ thickness was obtained, centered at the L4-L5 vertebral disc space using $170 \mathrm{~m} \AA$ with a scanning time of two seconds and a 512 matrix. The visceral and subcutaneous AT boundary was defined using a manual cursor, and adipose tissue areas were determined using commercially available software (Slice-OMatic, Tomovision, Montreal, Canada).

CT was also used to measure cross-sectional area (CSA) of mid-thigh muscle and adipose tissue and to characterize muscle attenuation. An anterior-posterior scout scan of the entire femur was used to localize the mid-thigh position. With the subject supine, a $10 \mathrm{~mm}$ cross-sectional scan of the dominant leg was obtained at the midpoint. The scanning parameters for this image were $120 \mathrm{kVp}$ and $200-250 \mathrm{~m} \AA$. This protocol has been utilized elsewhere [10].

Image analysis of adipose tissue and skeletal muscle CSAs of the thigh were calculated from the axial CT images using commercially available software (Slice-O-Matic, Tomovision, Montreal, Canada). Briefly, the mean attenuation coefficient values of muscle within the regions outlined on the images were determined by averaging the CT number (pixel intensity) in Hounsfield units (HU). The methodological variability of this measure is quite small [26]. Skeletal muscle and adipose tissue areas were calculated by the range of attenuation values for skeletal muscle (0 to $100 \mathrm{HU})$, normal density muscle (35-100 HU), and adipose (-190 to $-30 \mathrm{HU}$ ) tissue. Intermuscular adipose tissue (IMAT) was distinguished from the subcutaneous (SUBQ) adipose tissue by manually drawing a line along the deep fascial plane surrounding the thigh muscles. Quadriceps muscles were separated from hamstring muscles with manual tracing. 
Two additional reviewers analyzed thigh and abdominal scans from five randomly selected participants from this project and interrater reliability was assessed using a twoway mixed effects ANOVA model with SPSS 17.0 (SPSS Inc., Chicago, IL). The interclass correlation coefficient (ICC) was nonsignificant $(P>.99)$.

2.8. Isokinetic Strength Testing. At baseline and followup visits, isokinetic strength of the knee extensors was determined at $60 \%$ s with a dynamometer (model 125 AP, KinCom, Chattanooga, TN). The right leg was tested unless it was injured or weaker by self-report or restricted in motion. After instruction on the procedure, the participant was positioned so that the lateral femoral epicondyle of the knee joint was aligned with the rotational axis of the dynamometer. The participant's leg was weighed for gravity correction, and start-stop angles were set at $90^{\circ}$ and $30^{\circ}$. Two practice trials were performed at 50\% effort to familiarize the participant with the procedure and to provide a warmup period. Each participant performed at least three maximal efforts. Beginning with the first maximal effort, the torque production over the entire range of motion was plotted, and the plot of each subsequent effort was overlaid on the previous efforts until three similar curves were obtained. Participants were not asked to perform more than six trials. Maximal torque production was recorded as the mean peak torque production from three similar trials. This methodology was used for the Health ABC Study [9]. Additionally, specific torque was calculated for each participant (knee extensor strength per unit area of the quadriceps) and used as a measure of muscle quality in the quadriceps.

2.9. Statistical Analyses. This paper focuses on BL and 6 month followup (6FU) data only. The changes in body composition and strength measures were determined by calculating the difference between the BL and 6FU values. The mean change for each body composition measure was calculated and then stratified by randomization assignment. Data were tested for normality. When normal, the Student's $t$-test was used to determine the significance of the differences in mean change between groups and a paired $t$-test was used to determine if the mean change within each group was significant from $\mathrm{BL}$ to $6 \mathrm{FU}$. If the data were not normally distributed, the Wilcoxon Rank-Sum test was used to determine the significance of the differences in data distributions between randomization groups and the Wilcoxon Signed-Rank test was used to determine the significance of changes in data distributions within each group from $\mathrm{BL}$ to $6 \mathrm{FU}$.

Correlation coefficients were used to quantify the relationships between the body composition measures and performance measures with Pearson coefficients used with normal variables and Spearman coefficients for nonnormal variables. The correlation coefficients and their associated $P$-values were used to determine if these relationships were significant.

Note that all values reported in tables are means and that a negative mean change denotes a decrease from BL to
6FU and a positive mean change denotes an increase from BL to 6FU. An alpha level of 0.05 was used as the threshold of significance. All analyses were performed using SAS 9.2 statistical software (SAS Institute, Inc.), except for the ICC described above.

\section{Results}

3.1. Baseline. Study participants $(N=36)$ averaged 70.3 \pm 5.9 years of age, weighed, on average, $87.9 \pm 8.9 \mathrm{~kg}$ with a mean BMI of $32.9 \pm 3.2 \mathrm{~kg} / \mathrm{m}^{2}$, classifying them as overweight to moderately obese at baseline [27]. All participants were nonsmokers. The population was $16.7 \%$ black and $16.7 \%$ male (Table 1 ). All participants, with the exception of one in the PA+SA group, were followed up to their 6FU visits. The participant dropped out of the study for personal reasons within the first phase of the intervention. SPPB data were missing for one participant at $6 \mathrm{FU}$, in addition to the one dropout, due to an examiner error. Strength data is incomplete for three participants, in addition to the one dropout. One participant in the PA+SA group was unable to complete the test at both $\mathrm{BL}$ and 6FU due to bilateral knee replacement. Two participants, both in $\mathrm{PA}+\mathrm{WL}$ are missing 6FU strength data due to examiner errors. Additionally, CT data were incomplete for four participants, in addition to the one dropout. In the $\mathrm{PA}+\mathrm{SA}$ group, one participant had metal in their back and abdominal scans were unable to be obtained. Similarly, one person in this group had a hip replacement and all thigh measures. In the PA+WL group, one person was missing abdominal and one person was missing thigh scans due to metal deposits in the body.

There were no statistically significant differences between the $\mathrm{PA}+\mathrm{WL}$ and $\mathrm{PA}+\mathrm{SA}$ groups for baseline demographic, anthropometric, body composition, bone, strength, and functional characteristics, except for total SPPB score and total abdominal fat CSA (Tables 1 and 2) which were marginally significant. When total SPPB score was compartmentalized by component, there were no intergroup differences for any of the 3 component scores. Also, there were no significant differences at BL between intervention groups in self-reported PA levels as measured by the CHAMPS questionnaire $(P=.17)$.

3.2. Intervention Efficacy and Adherence. At 6FU, selfreported moderate PA increased uniformly in both intervention groups (by $222.9 \pm 329.2 \mathrm{~min} /$ week in PA+WL and $199.0 \pm 319.1 \mathrm{~min} /$ week in PA+SA), indicating an equally strong adherence to the PA program by both groups. In addition, $62 \%$ of the participants in the PA+WL group achieved $50 \%$ of their WL goal by 6 months (half of the intervention length), with $69 \%$ of these participants meeting or exceeding the weight loss goal. In addition, participants in the PA+WL group achieved, on average, a 5.5\% weight reduction ( $79 \%$ of the $7 \%$ weight loss goal).

3.3. Anthropometrics, Body Composition (DXA), and Bone Mass. The PA+WL group decreased their mean waist 
TABLE 1: Baseline demographic variables.

\begin{tabular}{|c|c|c|c|}
\hline & $\begin{array}{c}\text { Physical Activity }+ \text { Weight Loss }(N=21) \\
\text { Mean change }(\mathrm{BL}-6 \mathrm{FU})\end{array}$ & $\begin{array}{c}\text { Physical Activity }+ \text { Successful Aging }(N=15) \\
\text { Mean change (BL-6FU) }\end{array}$ & $P$-value \\
\hline Age (yrs) & $70.6(5.9)^{\#}$ & $69.9(5.9)$ & .80 \\
\hline Gender $(\%)$ & & & .68 \\
\hline Male & $4(19.0)$ & $2(13.3)$ & \\
\hline Female & $17(81.0)$ & $13(86.7)$ & \\
\hline Race (\%) & & & .20 \\
\hline White & $19(90.5)$ & $11(73.3)$ & \\
\hline African American & $2(9.5)$ & $4(26.7)$ & \\
\hline Education (\%) & & & .84 \\
\hline High school/GED & $13(65.0)$ & $10(66.7)$ & \\
\hline College & $6(30.0)$ & $2(13.3)$ & \\
\hline Other & $1(5.0)$ & $3(20.0)$ & \\
\hline Household income (\$thousand/year) (\%) & & & .99 \\
\hline$<\$ 50 \mathrm{~K}$ & $13(61.9)$ & $9(60.0)$ & \\
\hline$>\$ 50 \mathrm{~K}$ & $3(14.3)$ & $3(20.0)$ & \\
\hline Do not Know/Refused & $5(23.8)$ & $3(20.0)$ & \\
\hline
\end{tabular}

${ }^{\#} \pm$ Standard deviation.

circumference $(-4.0 \pm 7.5 \mathrm{~cm}, P=.03)$, body weight $(-4.9$ $\pm 4.8 \mathrm{~kg}, P<.0001)$ and BMI $\left(-1.7 \pm 1.7 \mathrm{~kg} / \mathrm{m}^{2}, P<.0001\right)$ significantly from baseline to $6 \mathrm{FU}$. The $\mathrm{PA}+\mathrm{SA}$ group did not experience a significant mean change in any of these three measures (Table 3). The effects of weight loss in addition to regular PA were examined for several body composition measures using DXA (Table 3). The PA+WL group lost a significant amount of total body fat $(-4.4 \pm 3.2 \mathrm{~kg}, P<$ $.0001)$ whereas the PA+SA group did not $(0.6 \pm 2.1 \mathrm{~kg}$, $P=.27)$. Participants' total body and total hip BMD were unchanged from $\mathrm{BL}$ to $6 \mathrm{FU}$ for both intervention groups (Table 3).

3.4. Body Composition-CT. The PA+WL group lost significant amounts of total abdominal fat $(P<.01)$, VAT $(P<.01)$ and SAT $(P=.02)$ from BL to $6 \mathrm{FU}$, compared to no change in the PA+SA group $(P=.8, .46$ and .84 , resp.) (Table 3). The mean changes in total abdominal fat and VAT were both significantly different between intervention groups $(P=.01$ and $P<.01$, resp.) (Table 3$)$. The $\mathrm{PA}+\mathrm{WL}$ group lost significant amounts of both total muscle $(-2.3 \pm$ $\left.3.9 \mathrm{~cm}^{2}, P=.03\right)$ and adipose $\left(-18.1 \pm 17.5 \mathrm{~cm}^{2}, P<.01\right)$ tissue CSA, as well as IMAT $\left(-2.0 \pm 2.9 \mathrm{~cm}^{2}, P<.01\right)$ in the thigh. In comparison, the PA+SA group did not manifest significant decreases in any of these measures and actually gained some total thigh muscle CSA $\left(1.5 \pm 3.4 \mathrm{~cm}^{2}, P=.13\right)$. Mean change in total muscle CSA was the only one of these measures that differed significantly between intervention groups $(P<.01)$. Change in IMAT for both intervention groups is displayed in Figure 1.

The PA+WL group lost only $2.2 \% \pm 3.6$ of their baseline total muscle CSA as opposed to $12.9 \% \pm 10.7$ of their baseline total adipose CSA in the thigh. The discrepancy between total thigh fat and muscle loss is displayed in Figures 2 and 3. Despite the individual statistical significance of both these

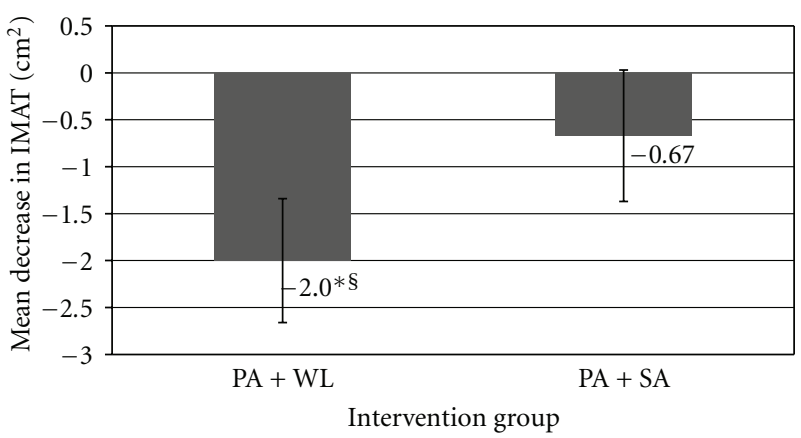

$$
\begin{aligned}
& { }^{*} \text { Significant decrease from BL to } 6 \mathrm{FU}(P<.05) \\
& \S_{\text {No significant between group difference }(P=.19)} \\
& \text { Error bars denote standard error }
\end{aligned}
$$

FIGURE 1: Mean change in IMAT $\left(\mathrm{cm}^{2}\right)$ from baseline to 6-month followup by intervention group.

changes, the participants in the PA+WL group lost a much greater proportion of their thigh adipose CSA as compared to thigh muscle CSA from BL to 6FU (Figures 2 and 3 ). When the quadriceps was isolated, the $\mathrm{PA}+\mathrm{WL}$ group displayed significant decreases in total muscle CSA $\left(-1.6 \pm 2.4 \mathrm{~cm}^{2}\right.$, $P=.02)$ whereas the PA+SA group did not $\left(-1.4 \pm 3.9 \mathrm{~cm}^{2}\right.$, $P=.31)$.

The mean muscle attenuation values increased significantly in the PA+WL group $(1.3 \pm 1.2 \mathrm{HU}, P<.01)$ as well as in the PA+SA group $(0.9 \pm 1.2, P=.02)$ (Table 3$)$, indicating that participants' muscle tissue lipid content (fat infiltration) decreased in both intervention groups. Although the PA+WL groups' muscle tissue lipid content decreased to a greater degree than the PA+SA group, there was no significant difference in mean change in muscle fat-infiltration between groups $(P=.32)$. Similar patterns were observed when 
TABLE 2: Baseline anthropometric, body composition, bone mass, muscle strength, and physical function by intervention group.

\begin{tabular}{|c|c|c|c|}
\hline & $\begin{array}{l}\text { Physical Activity }+ \text { Weight Loss }(N=20) \\
\text { Mean change }(\text { BL-6FU) }\end{array}$ & $\begin{array}{l}\text { Physical Activity }+ \text { Successful Aging }(N=14) \\
\text { Mean change }(\text { BL-6FU) }\end{array}$ & $P$-value \\
\hline \multicolumn{4}{|l|}{ Anthropometric } \\
\hline Waist circumference, $\mathrm{cm}$ & $108.8(7.2)^{\#}$ & $105.1(8.8)$ & .22 \\
\hline Body weight, $\mathrm{kg}$ & $89.8(10.0)$ & $85.4(6.5)$ & .21 \\
\hline Height, $\mathrm{cm}$ & $164.1(8.4)$ & $163.2(5.2)$ & .77 \\
\hline BMI, $\mathrm{kg} / \mathrm{m}^{2}$ & $33.6(3.3)$ & $32.1(3.0)$ & .30 \\
\hline \multicolumn{4}{|l|}{ DXA } \\
\hline Percent body fat & $43.0(5.4)$ & $42.5(6.1)$ & .73 \\
\hline Total fat mass, $\mathrm{kg}$ & $38.0(5.9)$ & $35.9(6.5)$ & .61 \\
\hline Total lean mass, kg & $48.2(7.6)$ & $46.1(5.2)$ & .55 \\
\hline Appendicular lean mass, $\mathrm{kg}$ & $20.6(3.7)$ & $19.7(2.8)$ & .47 \\
\hline Total body BMD, $\mathrm{g} / \mathrm{cm}^{2}$ & $1.14(0.12)$ & $1.11(0.15)$ & .53 \\
\hline Total hip BMD, $\mathrm{g} / \mathrm{cm}^{2}$ & $0.93(0.11)$ & $0.93(0.15)$ & .91 \\
\hline \multicolumn{4}{|l|}{ Abdominal CT } \\
\hline Total, $\mathrm{cm}^{2}$ & $661.5(134.1)$ & $569.5(97.6)$ & $.04^{*}$ \\
\hline Visceral fat, $\mathrm{cm}^{2}$ & $217.7(61.3)$ & $179.8(47.9)$ & .06 \\
\hline Subcutaneous fat, $\mathrm{cm}^{2}$ & $443.7(124.5)$ & $389.1(93.4)$ & .17 \\
\hline \multicolumn{4}{|l|}{ Right thigh CT } \\
\hline Total fat, $\mathrm{cm}^{2}$ & $150.8(52.4)$ & $137.9(47.8)$ & .47 \\
\hline Subcutaneous, $\mathrm{cm}^{2}$ & $133.2(52.8)$ & $119.8(47.4)$ & .45 \\
\hline Intermuscular fat, $\mathrm{cm}^{2}$ & $12.5(3.6)$ & $13.4(5.5)$ & .57 \\
\hline Muscle mass (CSA), $\mathrm{cm}^{2}$ & $102.3(23.2)$ & $102.5(90.2)$ & .99 \\
\hline Muscle density, HU & $39.6(3.1)$ & $40.1(3.3)$ & .62 \\
\hline Lean muscle mass, $\mathrm{cm}^{2}$ & $68.8(18.9)$ & $71.7(21.1)$ & .64 \\
\hline \multicolumn{4}{|l|}{ Right quadriceps CT } \\
\hline Muscle mass, $\mathrm{cm}^{2}$ & $49.2(10.6)$ & $50.1(10.8)$ & .81 \\
\hline Muscle density, HU & $44.2(3.7)$ & $44.6(3.6)$ & .71 \\
\hline Lean muscle mass, $\mathrm{cm}^{2}$ & $37.7(10.7)$ & $39.6(11.9)$ & .64 \\
\hline Specific torque $\left(\mathrm{N} \cdot \mathrm{m} / \mathrm{cm}^{2}\right)$ & $2.2(0.3)$ & $2.2(0.5)$ & .65 \\
\hline \multicolumn{4}{|l|}{ Knee extensor strength } \\
\hline Peak torque, $\mathrm{N} \cdot \mathrm{m}$ & $105.9(32.2)$ & $110.8(23.7)$ & .66 \\
\hline Average torque, $\mathrm{N} \cdot \mathrm{m}$ & $85.3(25.2)$ & $89.7(24.6)$ & .62 \\
\hline \multicolumn{4}{|l|}{$\mathrm{SPPB}$} \\
\hline Total & $9.7(1.4)$ & $10.7(1.1)$ & $.05^{*}$ \\
\hline Chair stand score $(0-4)$ & $2.2(1.1)$ & $2.7(1.0)$ & .15 \\
\hline Balance score $(0-4)$ & $3.7(0.6)$ & $4.0(0)$ & .06 \\
\hline Gait speed score (0-4) & $3.8(0.5)$ & $3.9(0.3)$ & .48 \\
\hline
\end{tabular}

\# \pm Standard deviation.

* Significant at $P<.05$.

the quadriceps was isolated, with both groups showing significant decreases in fat-infiltration of the quadriceps (Table 3).

3.5. Knee Extensor Strength. The PA+WL group lost $12.4 \%$ $(P=.01)$ of peak isokinetic knee extensor strength from $\mathrm{BL}$ to $6 \mathrm{FU}$; conversely, the PA+SA group did not $(1 \%, P=$ $.01)$ (Table 3). However, these changes were not statistically significantly different between intervention groups $(P=.11)$ Similar patterns were observed for mean change in specific torque, the $\mathrm{PA}+\mathrm{WL}$ group had a $11.1 \% \mathrm{~N} \cdot \mathrm{m} \cdot \mathrm{cm}^{-2}$ decrease in mean specific torque compared to the $<0.1 \% \mathrm{~N} \cdot \mathrm{m} \cdot \mathrm{cm}^{-2}$ decrease in the PA+SA group, but these were not statistically significant, $P=.11$ and $P=.99$, respectively.

3.6. Physical Function. Both intervention groups uniformly improved physical function as measured by the SPPB. There were no intergroup differences in mean increase in SPPB score $(P=.81)$ (Table 3$)$. However, the PA+WL group significantly improved their SPPB scores by $0.70 \pm 1.42$, $P=.04$ whereas the PA+SA group did not $(0.50 \pm 0.94$, $P=.13)$. 
TABle 3: Mean changes in anthropometric, body composition, bone mass, muscle strength, and physical function measures from baseline to 6-month followup by intervention group.

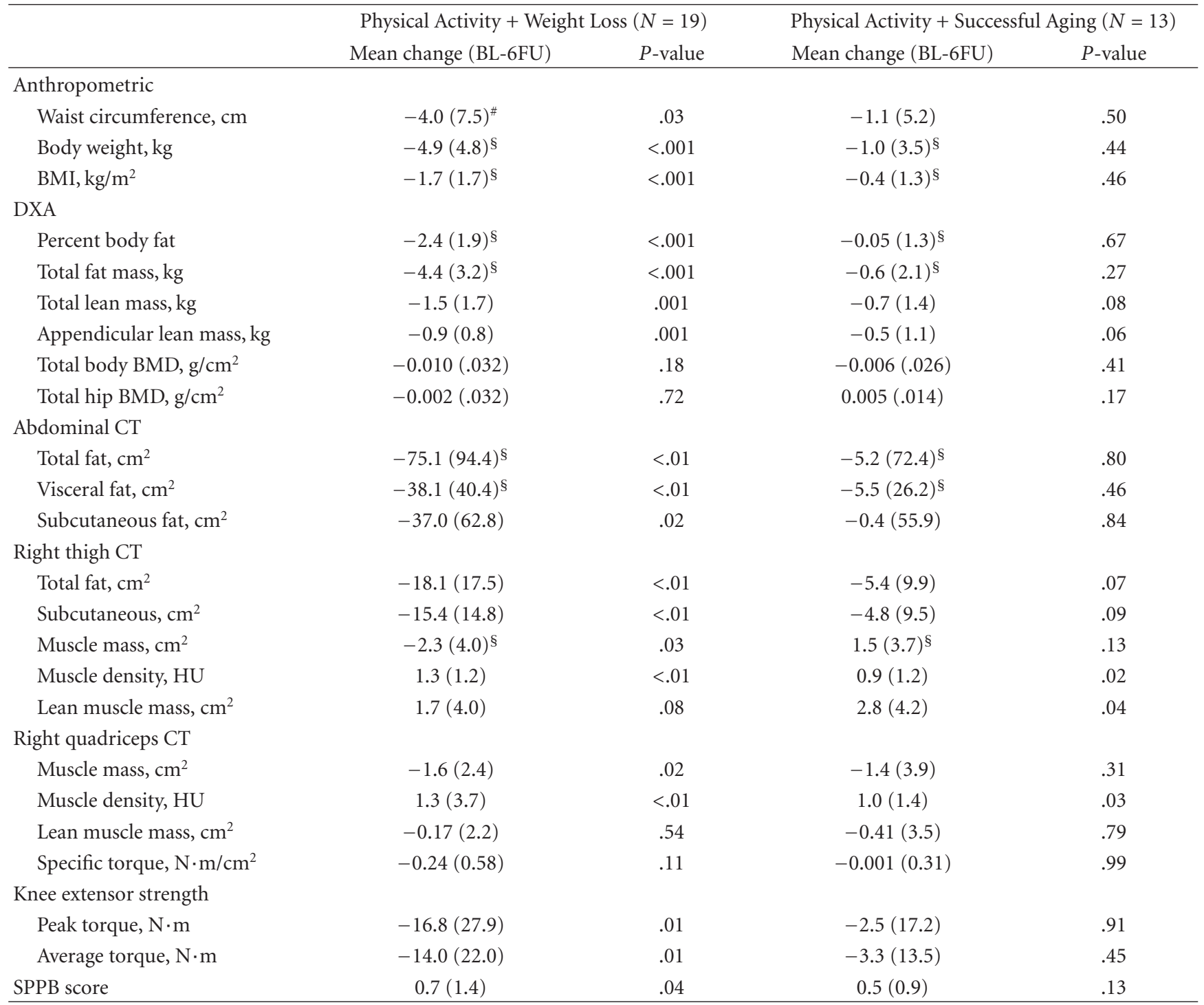

\# \pm Standard deviation.

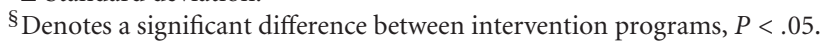

TABLE 4: Correlations between change in body composition measures with change in muscle strength and physical function.

\begin{tabular}{|c|c|c|c|c|c|c|c|}
\hline & $\begin{array}{c}\text { Total } \\
\text { abdominal } \\
\text { fat }\end{array}$ & $\begin{array}{c}\text { SAT- } \\
\text { abdominal }\end{array}$ & $\begin{array}{c}\text { VAT- } \\
\text { abdominal }\end{array}$ & $\begin{array}{l}\text { Thigh fat } \\
\text { CSA }\end{array}$ & $\begin{array}{c}\text { Thigh muscle } \\
\text { CSA }\end{array}$ & $\begin{array}{l}\text { Thigh muscle } \\
\text { density }\end{array}$ & Thigh IMAT \\
\hline Total SPPB & $-0.47^{\S}$ & $-0.38^{*}$ & $-0.53^{\S}$ & -0.34 & -.003 & -0.08 & $-0.41^{*}$ \\
\hline Chair stand component & $-0.44^{*}$ & $-0.42^{*}$ & $-0.36^{*}$ & -0.28 & -0.07 & 0.09 & $-0.39^{*}$ \\
\hline Peak torque & 0.14 & 0.12 & 0.23 & 0.10 & 0.05 & -0.27 & 0.02 \\
\hline
\end{tabular}

${ }^{*}$ Significant at $P<.05$ level.

§ignificant at $P<.01$ level.

3.7. Relationship between Body Composition and Strength with Physical Function. Changes in fat tissue were more closely related to change in total and chair stand component of the SPPB score than were changes in muscle tissue and strength. The mean change in chair stand and total SPPB score were strongly inversely correlated $(P<.05)$ with mean change in total visceral and subcutaneous abdominal fat as well as intermuscular adipose tissue in the thigh (Table 4). Total SPPB, chair stands SPPB score and strength was not strongly correlated with mean change in any of the lean tissue or 


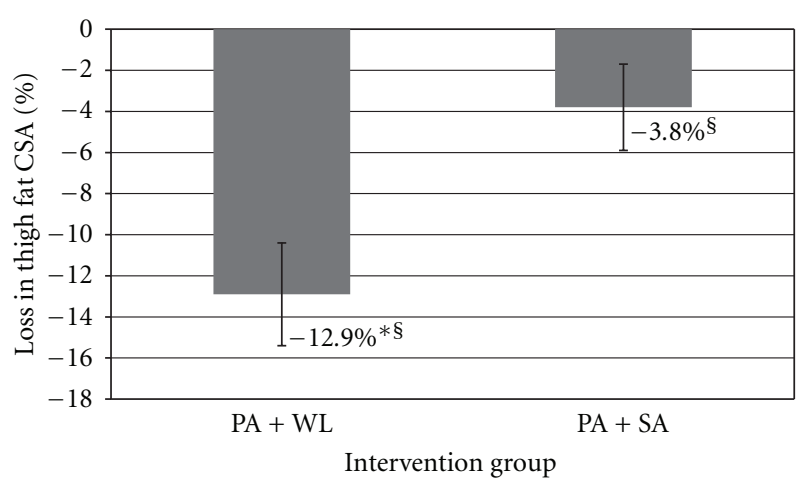

* Significant change from BL to $6 \mathrm{FU}(P<.05)$

$\S_{\text {Significant between group difference }(P=.02)}$

Error bars denote standard error

Figure 2: Percent change in total thigh fat CSA from Baseline to 6-month followup by intervention group.



* Significant decrease from BL to $6 \mathrm{FU}(P<.01)$

$\S$ Significant between group difference $(P<.01)$

Error bars denote standard error

Figure 3: Percent change in total thigh muscle CSA from baseline to 6-month followup by intervention group.

muscle quality measures. In addition, mean change in total fat CSA in the thigh was much more closely related to change in chair stand and total SPPB score than total thigh muscle CSA (Table 4).

\section{Discussion}

The primary focus of this study was to assess the added effects of weight loss and PA on physical function in older adults and the extent to which changes might be mediated by muscle mass, muscle fat infiltration, and muscle strength. The PA+WL group lost a significant amount of both total muscle and fat CSA from BL to 6FU, as compared to the $\mathrm{PA}+\mathrm{SA}$ group, which did not manifest significant changes in these measures. These results are similar to those in previous studies, as it has been shown that weight loss induces a loss of lean mass in older adults. In other studies with a weight loss only comparison group, a regular PA program consisting of walking, resistance, and balance training attenuated agerelated loss of muscle mass [10, 28].

As anticipated, the PA+WL group significantly decreased the lipid content of their muscle tissue, as measured by muscle attenuation, but this increase was not enough to attenuate the affects of the decreases in muscle mass on strength, as the PA+WL group lost a significant amount of strength from $\mathrm{BL}$ to $6 \mathrm{FU}$. This finding is contradictory to a similar study, conducted by Wang et al., comparing the effects of WL and PA to a true control group on strength and body composition, which reported an $8 \%$ increase in eccentric knee strength [15]. Participants in that study were diagnosed with osteoarthritis in the knee, so it is possible that the benefits of WL and regular PA were accentuated in this population. These differing results could also be a result of key differences in the WL interventions. The WL intervention in the Wang et al. study provided meal replacement shakes and bars for two meals and a menu plan with recipes for the third. The investigators did this to better control the percentage of caloric intake from protein, fat, and carbohydrates. The WL intervention in this study was not as strict, simply concentrating on a lowfat, low-calorie healthy eating pattern. These differences are important because protein intake has been shown to affect muscle protein synthesis and, in turn, muscle mass in older adults [29]. Perhaps WL and PA randomized controlled trials conducted in older adults should include a higher protein intake.

The PA+SA group lost some nominal muscle strength. A loss of strength is expected with aging, so that this may represent an attenuation of this expected loss. Indeed, this concurs with the results a previous study of the LIFE$\mathrm{P}$ Study, which demonstrated that a regular, moderate intensity PA program can attenuate the loss strength in older adults [10]. When mean change in knee extensor strength was compared between groups, there was a trend towards statistical significance $(P=.11)$; which suggests that intentional weight loss with regular PA accelerates the loss of strength with age, as compared to regular PA alone. The results of this study also differed from the study by Wang et al. [15] in respect to muscle quality. In this study, those in the PA+WL group decreased their muscle quality (suggestive but not statistically significant, $P=.11$ ), compared to the participants in their study who significantly increased their muscle quality [15]. This may be due to the fact that muscle quality was calculated differently in this study and for the differences in the two WL interventions described above. The PA+SA group experienced virtually no change in muscle quality from BL to 6FU, a result consistent with LIFE-P [10].

The PA+WL group improved function to a greater degree than the PA+SA group despite losing significant amounts of both lean mass and strength. This is because participants in this group lost 6-fold more fat mass than lean mass in the thigh, which resulted in a more optimal lean mass to fat mass ratio and were probably better able to carry their weight. These results suggest that the loss of fat is important in improving function in generally healthy, overweight to 
moderately obese adults over the age of 60 . The strong correlations between mean change in chair stands and total SPPB scores with mean change in total visceral and subcutaneous abdominal fat as well as intermuscular adipose tissue in the thigh suggest that this improvement in function was due to losses in adipose tissue rather than gains or attenuation of losses in muscle mass. These findings seem to suggest that older adults can improve function while losing both fat and muscle mass, as long as the individual loses a significantly greater proportion of fat mass compared to muscle mass. This finding is consistent with previous studies assessing the effects of WL with regular PA in older adults with knee osteoarthritis [30-32]. It is worth noting that this intervention trial is still ongoing so it is possible that these may only be short-term effects. It will be important to observe any further changes in body composition and function that take place during the longer followup period.

Participants in the PA+WL group lost a significant amount of both visceral (17.5\%) and thigh (11.6\%) subcutaneous (i.e., gluteofemoral) fat. The latter has been shown to possess certain protective properties including independent associations with lower total and low-density lipoprotein cholesterol as well as vascular health benefits, such as decreased aortic calcification and arterial stiffness [33-37]. Participants in this study were in the overweight to moderately obese BMI categories upon enrollment and the functional benefit was clear. However, weight loss interventions involving older adults should evaluate relative effects of changes in fat distribution on metabolic function.

This study has several strengths. Both interventions were shown to be effective, as shown by outstanding efficacy and adherence, and functional outcomes were used to measure physical function rather than self-reported function. This eliminates any potential recall bias. Also, that there were limited physical functioning exclusion and inclusion criteria; meaning the results of this study are generalizable to both low and high physically functioning older adults. However, future studies could be designed to recruit a higher number of lower functioning people, as this population was fairly high functioning at baseline. One limitation of this study is that it lacks other control groups, which would consist of participants receiving either a WL intervention or health education program, making it difficult to distinguish the effect of weight loss alone from the activity intervention [10]. Additionally, the participants were fairly healthy, thus the findings may not be relevant to more frail older adults.

In conclusion, a physical activity plus weight loss intervention program significantly improved function and decreased both fat and muscle CSA, compared to PA plus successful aging health education in generally healthy, overweight to moderately obese adults over the age of 60 . While, PA+WL resulted in significant decreases in knee extensor strength compared with PA+SA in this population, this did not translate into functional decline. This study also demonstrated that $\mathrm{PA}+\mathrm{WL}$ conferred a 6 -fold decrease in thigh fat mass compared to lean mass and that this more optimal lean mass to fat mass ratio resulted in improved physical function. The obesity epidemic is affecting all age groups and could decrease prospects for an active life expectancy in older adults. The potential to improve mobility and decrease disability in older adults is substantial. These findings provide important novel insight into the risks, benefits and mechanisms of weight loss in overweight to moderately obese older adults.

\section{Acknowledgments}

This work was supported by Centers for Disease Control and Prevention Cooperative Agreement no. 1 U48 DP000025 and the Center for Aging and Population Health at the Graduate School of Public Health at the University of Pittsburgh.

\section{References}

[1] D. T. Villareal, C. M. Apovian, R. F. Kushner, and S. Klein, "Obesity in older adults: technical review and position statement of the American Society for Nutrition and NAASO, The Obesity Society," American Journal of Clinical Nutrition, vol. 82, no. 5, pp. 923-934, 2005.

[2] R. Sturm, J. S. Ringel, and T. Andreyeva, "Increasing obesity rates and disability trends," Health Affairs, vol. 23, no. 2, pp. 199-205, 2004.

[3] A. B. Newman, V. Kupelian, M. Visser et al., "Strength, but not muscle mass, is associated with mortality in the health, aging and body composition study cohort," Journals of Gerontology Series A: Biological Sciences and Medical Sciences, vol. 61, no. 1, pp. 72-77, 2006.

[4] M. Visser, B. H. Goodpaster, S. B. Kritchevsky et al., "Muscle mass, muscle strength, and muscle fat infiltration as predictors of incident mobility limitations in well-functioning older persons," Journals of Gerontology Series A: Biological Sciences and Medical Sciences, vol. 60, no. 3, pp. 324-333, 2005.

[5] S. V. Brooks and J. A. Faulkner, "Skeletal muscle weakness in old age: underlying mechanisms," Medicine and Science in Sports and Exercise, vol. 26, no. 4, pp. 432-439, 1994.

[6] W. R. Frontera, V. A. Hughes, K. J. Lutz, and W. J. Evans, "A cross-sectional study of muscle strength and mass in 45- to 78-yr-old men and women," Journal of Applied Physiology, vol. 71, no. 2, pp. 644-650, 1991.

[7] B. H. Goodpaster, S. W. Park, T. B. Harris et al., "The loss of skeletal muscle strength, mass, and quality in older adults: the Health, Aging and Body Composition Study," Journals of Gerontology Series A: Biological Sciences and Medical Sciences, vol. 61, no. 10, pp. 1059-1064, 2006.

[8] B. H. Goodpaster, D. E. Kelley, F. L. Thaete, J. He, and R. Ross, "Skeletal muscle attenuation determined by computed tomography is associated with skeletal muscle lipid content," Journal of Applied Physiology, vol. 89, no. 1, pp. 104-110, 2000.

[9] B. H. Goodpaster, C. L. Carlson, M. Visser et al., "Attenuation of skeletal muscle and strength in the elderly: the health $\mathrm{ABC}$ study," Journal of Applied Physiology, vol. 90, no. 6, pp. 21572165, 2001.

[10] B. H. Goodpaster, P. Chomentowski, B. K. Ward et al., "Effects of physical activity on strength and skeletal muscle fat infiltration in older adults: a randomized controlled trial," Journal of Applied Physiology, vol. 105, no. 5, pp. 1498-1503, 2008.

[11] R. N. Baumgartner, S. J. Wayne, D. L. Waters, I. Janssen, D. Gallagher, and J. E. Morley, "Sarcopenic obesity predicts instrumental activities of daily living disability in the elderly," Obesity Research, vol. 12, no. 12, pp. 1995-2004, 2004. 
[12] E. Zoico, V. Di Francesco, J. M. Guralnik et al., "Physical disability and muscular strength in relation to obesity and different body composition indexes in a sample of healthy elderly women," International Journal of Obesity, vol. 28, no. 2, pp. 234-241, 2004.

[13] A. B. Newman, J. S. Lee, M. Visser et al., "Weight change and the conservation of lean mass in old age: the Health, Aging and Body Composition Study," American Journal of Clinical Nutrition, vol. 82, no. 4, pp. 872-878, 2005.

[14] P. Chomentowski, J. J. Dubé, F. Amati et al., "Moderate exercise attenuates the loss of skeletal muscle mass that occurs with intentional caloric restriction-induced weight loss in older, overweight to obese adults," Journals of Gerontology Series: A Biological Sciences and Medical Sciences, vol. 64, no. 5, pp. 575-580, 2009.

[15] X. Wang, G. D. Miller, S. P. Messier, and B. J. Nicklas, "Knee strength maintained despite loss of lean body mass during weight loss in older obese adults with knee osteoarthritis," Journals of Gerontology Series A: Biological Sciences and Medical Sciences, vol. 62, no. 8, pp. 866-871, 2007.

[16] D. T. Villareal, M. Banks, D. R. Sinacore, C. Siener, and S. Klein, "Effect of weight loss and exercise on frailty in obese older adults," Archives of Internal Medicine, vol. 166, no. 8, pp. 860-866, 2006.

[17] W. J. Rejeski, R. A. Fielding, S. N. Blair et al., "The lifestyle interventions and independence for elders (LIFE) pilot study: design and methods," Contemporary Clinical Trials, vol. 26, no. 2, pp. 141-154, 2005.

[18] G. A. Bray, K. S. Polonsky, P. G. Watson et al., "The Diabetes Prevention Program: design and methods for a clinical trial in the prevention of type 2 diabetes," Diabetes Care, vol. 22, no. 4, pp. 623-634, 1999.

[19] A. B. Newman, C. M. Bayles, C. N. Milas et al., "The 10 keys to healthy aging: findings from an innovative prevention program in the community," Journal of Aging and Health, vol. 22, no. 5, pp. 547-566, 2010.

[20] J. M. Guralnik, E. M. Simonsick, L. Ferrucci et al., "A short physical performance battery assessing lower extremity function: association with self-reported disability and prediction of mortality and nursing home admission," Journals of Gerontology, vol. 49, no. 2, pp. M85-M94, 1994.

[21] A. L. Stewart, K. M. Mills, A. C. King, W. L. Haskell, D. Gillis, and P. L. Ritter, "CHAMPS physical activity questionnaire for older adults: outcomes for interventions," Medicine and Science in Sports and Exercise, vol. 33, no. 7, pp. 1126-1141, 2001.

[22] R. A. Fielding, J. Katula, M. E. Miller et al., "Activity adherence and physical function in older adults with functional limitations," Medicine and Science in Sports and Exercise, vol. 39, no. 11, pp. 1997-2004, 2007.

[23] M. Visser, T. Fuerst, T. Lang, L. Salamone, T. B. Harris, and F.T. Health, A. Absorptiometry, Body Composition Study DualEnergy X-Ray, and B.C.W. Group, "Validity of fan-beam dualenergy X-ray absorptiometry for measuring fat- free mass and leg muscle mass," Journal of Applied Physiology, vol. 87, no. 4, pp. 1513-1520, 1999.

[24] D. Gallagher, M. Visser, R. E. De Meersman et al., "Appendicular skeletal muscle mass: effects of age, gender, and ethnicity," Journal of Applied Physiology, vol. 83, no. 1, pp. 229-239, 1997.

[25] S. Sipilä, J. Multanen, M. Kallinen, P. Era, and H. Suominen, "Effects of strength and endurance training on isometric muscle strength and walking speed in elderly women," Acta Physiologica Scandinavica, vol. 156, no. 4, pp. 457-464, 1996.
[26] B. H. Goodpaster, F. L. Thaete, and D. E. Kelley, "Composition of skeletal muscle evaluated with computed tomography," Annals of the New York Academy of Sciences, vol. 904, pp. 1824, 2000.

[27] WHO, “Global Database on Body Mass Index," October 2010, http://apps.who.int/bmi/index.jsp?introPage=intro_3.html.

[28] E. P. Weiss, S. B. Racette, D. T. Villareal et al., "Lower extremity muscle size and strength and aerobic capacity decrease with caloric restriction but not with exercise-induced weight loss," Journal of Applied Physiology, vol. 102, no. 2, pp. 634-640, 2007.

[29] D. Paddon-Jones and B. B. Rasmussen, "Dietary protein recommendations and the prevention of sarcopenia," Current Opinion in Clinical Nutrition and Metabolic Care, vol. 12, no. 1, pp. 86-90, 2009.

[30] R. Christensen, E. M. Bartels, A. Astrup, and H. Bliddal, "Effect of weight reduction in obese patients diagnosed with knee osteoarthritis: a systematic review and meta-analysis," Annals of the Rheumatic Diseases, vol. 66, no. 4, pp. 433-439, 2007.

[31] S. P. Messier, R. F. Loeser, G. D. Miller et al., "Exercise and dietary weight loss in overweight and obese older adults with knee osteoarthritis: the arthritis, diet, and activity promotion trial," Arthritis and Rheumatism, vol. 50, no. 5, pp. 1501-1510, 2004.

[32] G. D. Miller, B. J. Nicklas, C. Davis, R. F. Loeser, L. Lenchik, and S. P. Messier, "Intensive weight loss program improves physical function in older obese adults with knee osteoarthritis," Obesity, vol. 14, no. 7, pp. 1219-1230, 2006.

[33] K. N. Manolopoulos, F. Karpe, and K. N. Frayn, "Gluteofemoral body fat as a determinant of metabolic health," International Journal of Obesity, vol. 34, no. 6, pp. 949-959, 2010.

[34] J. C. Seidell, L. Pérusse, J.-P. Després, and C. Bouchard, "Waist and hip circumferences have independent and opposite effects on cardiovascular disease risk factors: the Quebec Family Study," American Journal of Clinical Nutrition, vol. 74, no. 3, pp. 315-321, 2001.

[35] M. B. Snijder, M. Visser, J. M. Dekker et al., "Low subcutaneous thigh fat is a risk factor for unfavourable glucose and lipid levels, independently of high abdominal fat. The Health ABC Study," Diabetologia, vol. 48, no. 2, pp. 301-308, 2005.

[36] I. Ferreira, M. B. Snijder, J. W. R. Twisk et al., "Central fat mass versus peripheral fat and lean mass: opposite (adverse versus favorable) associations with arterial stiffness? The Amsterdam growth and health longitudinal study," Journal of Clinical Endocrinology and Metabolism, vol. 89, no. 6, pp. 2632-2639, 2004.

[37] M. B. Snijder, R. M. A. Henry, M. Visser et al., "Regional body composition as a determinant of arterial stiffness in the elderly: the Hoorn Study," Journal of Hypertension, vol. 22, no. 12, pp. 2339-2347, 2004. 


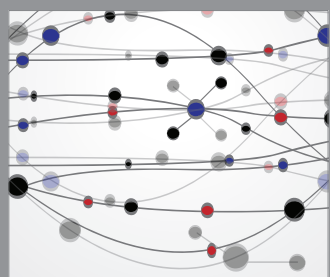

The Scientific World Journal
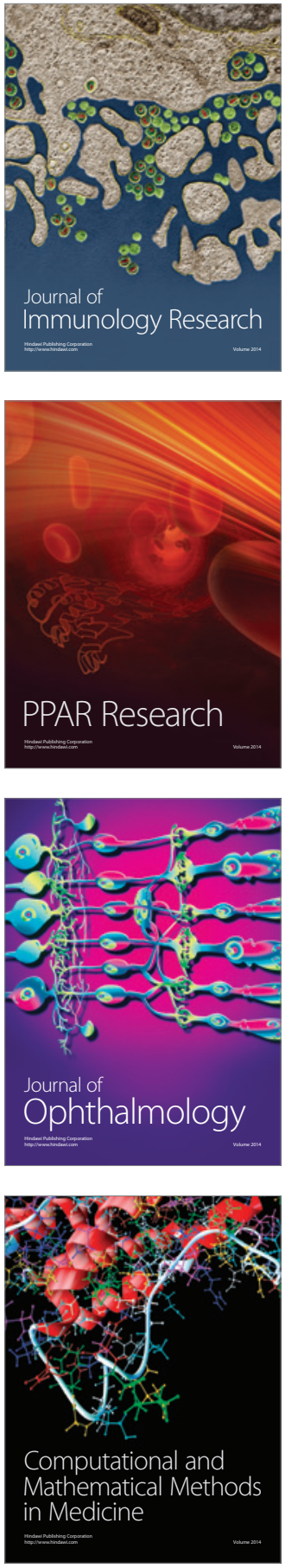



Gastroenterology

Research and Practice
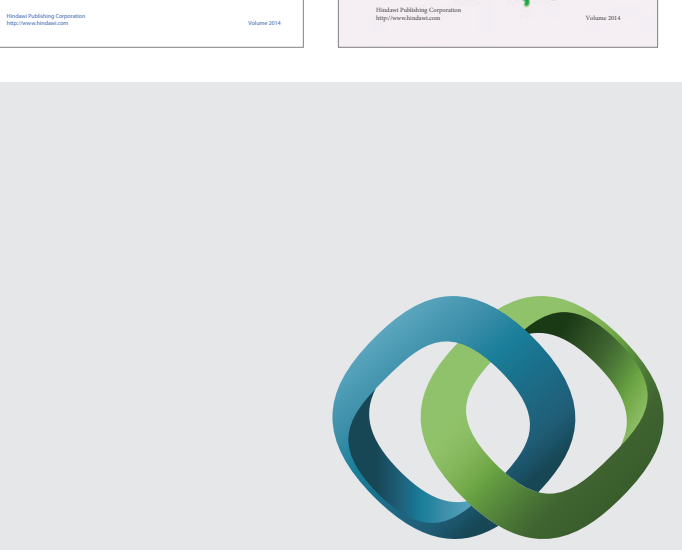

\section{Hindawi}

Submit your manuscripts at

http://www.hindawi.com
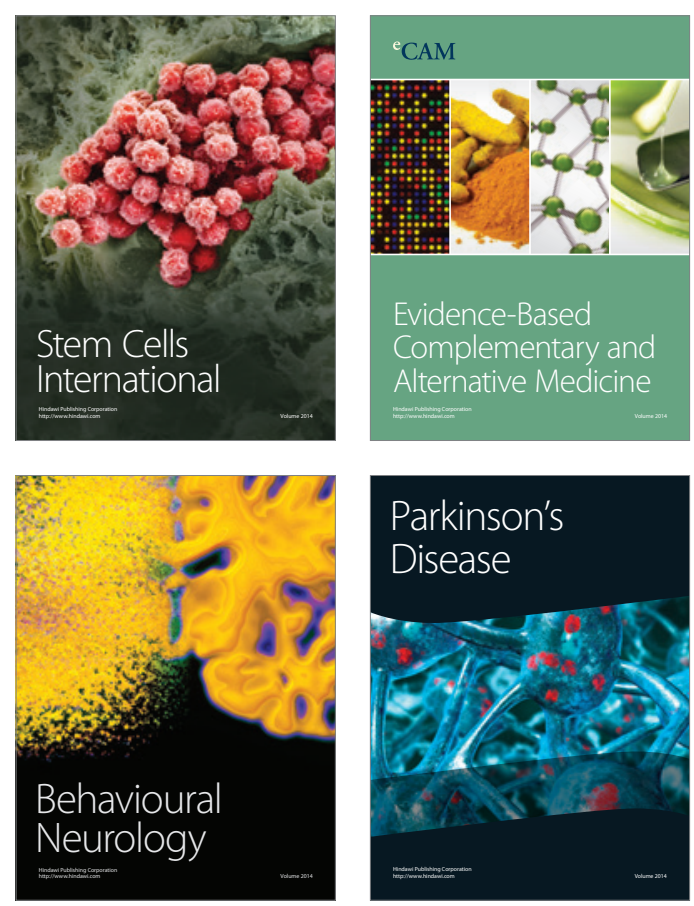

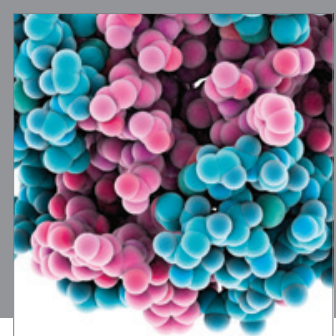

Journal of
Diabetes Research

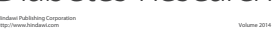



Disease Markers
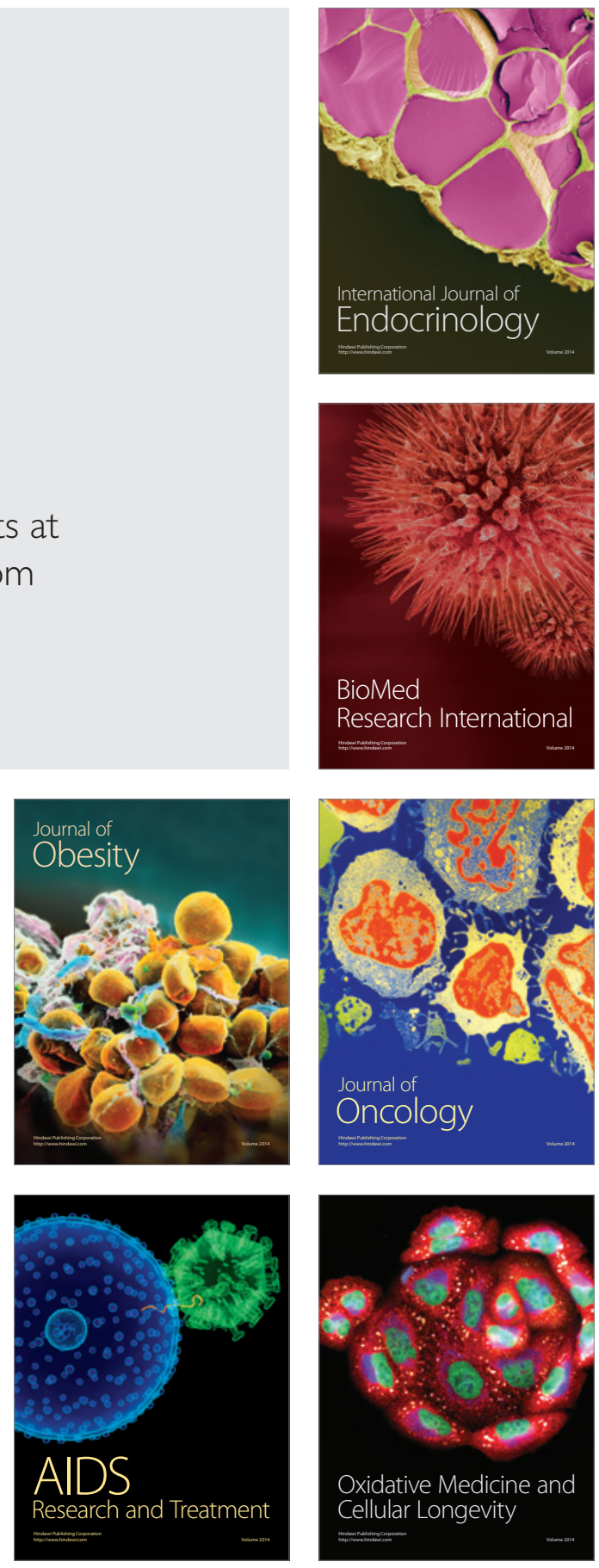